\title{
Obesity is a significant risk factor for breast cancer in Arab women
}

\author{
Naser Elkum ${ }^{1,4^{*}}$, Taher Al-Tweigeri ${ }^{2}$, Dahish Ajarim² ${ }^{2}$ Ali Al-Zahrani1 ${ }^{4}$, Suad M Bin Amer ${ }^{3}$ and Abdelilah Aboussekhra ${ }^{3}$
}

\begin{abstract}
Background: Breast cancer (BC) is the most common malignancy and the leading cause of cancer-related death amongst women worldwide. The risk factors of this disease are numerous, and their prevalence varies between racial and ethnic groups as well as geographical regions. Therefore, we sought to delineate the association of socio-demographic, reproductive and life-style related risk factors with breast cancer in the Arab population.

Methods: Unmatched case-control study was conducted in the kingdom of Saudi Arabia using 534 cases of histologically confirmed breast cancer and 638 controls. Controls were randomly selected from primary health care visits and were free of breast cancer. Unconditional logistic regression analysis was performed to estimate odds ratios (ORs) and to examine the predictive effect of each factor on risk for BC. All study participants were interviewed by trained interviewers at hospital (cases) or at primary health care centers (controls).

Results: A total of 1172 women were eligible for this study, of which 281 (24.0\%) were aged $\leq 35$ years, 22.9\% illiterate, $43.6 \%$ employed, $89.5 \%$ married, and $38.1 \%$ were obese. Grade III tumors constituted $38.4 \%$ of cases. Tumor stage I was 7.5\%; II, 50.7\%; II, 30.9\%; IV, 11.1\%. We have shown strong association between breast cancer among Arab females and obesity $(\mathrm{OR}=2.29,95 \% \mathrm{Cl} 1.68-3.13)$, positive family history of breast cancer $(\mathrm{OR}=2.31$, $95 \% \mathrm{Cl} 1.60-3.32)$, the use of hormonal replacement therapy ( $\mathrm{OR}=2.25,95 \% \mathrm{Cl} 1.65-3.08)$, post-menopause $(\mathrm{OR}=1.72,95 \% \mathrm{Cl} 1.25-2.38)$, lack of education $(\mathrm{OR}=9.09,95 \% \mathrm{Cl} 5.88-14.29)$, and never breastfeed $(\mathrm{OR}=1.89$, $95 \%$ Cl $1.19-2.94)$.
\end{abstract}

Conclusion: These results indicate the presence of classical risk factors established in the western countries, and also some specific ones, which may result from genetic and/or environmental factors. Thereby, these findings will be of great value to establish adequate evidence-based awareness and preventative measures in the Arab world.

Keywords: Breast cancer, Obesity, Risk factors, Epidemiology, Arab women

\section{Background}

Breast cancer is the most common malignancy and the leading cause of cancer-related death amongst women worldwide [1,2]. Similarly, in the kingdom of Saudi Arabia (KSA), breast cancer is currently the most common malignancy among females [3-5]. It represents $23 \%$ of the total number of cancer cases in the kingdom. The incidence of this disease is witnessing a gradual increase with total cancer cases diagnosed at an average annual age standardized rate (ASR) of 15.6/100,000 [6]. Breast cancer among Saudis

\footnotetext{
* Correspondence: nelkum@hotmail.com

'Division of Clinical Epidemiology, Sidra Medical and Research Centre, Doha, Qatar

${ }^{4}$ Department of Biostatistics, Epidemiology, and Scientific Computing, KFSH\&RC, MBC\#03, KSA, Riyadh, Saudi Arabia

Full list of author information is available at the end of the article
}

is characterized by high aggressiveness, poor clinicopathologic features and early onset [7-9]. Indeed, breast cancer cases tend to be found in younger women with median age of 47 years as compared to 63 in industrialized nations, and with advanced stage of the disease [3,9,10]. Young age at onset of breast cancer correlates with a worse prognosis irrespective of the menopausal status, since age remains a risk factor among premenopausal women [11].

A number of breast cancer-related etiological factors have been identified [12-15]. These include genetic, reproductive, environmental and socioeconomic risk factors [16]. In addition, it is becoming increasingly evident that obesity, young age at menarche, late age at first child, short period of lactation and being physically inactive are important risk factors for developing breast 
cancer in different countries. Furthermore, geographical, racial and ethnic distributions also have major effects on the incidence and the pathophysiology of the disease [1,17-21]. Notably, studies in developed countries with high prevalence of established risk factors showed that approximately $50 \%$ of breast cancer risk is attributable to the established factors [22]. However, the vast majority of these factors were identified and their effects were studied only on western populations. Furthermore, the Gail model on breast cancer risk assessment has been developed in order to predict the number of cancers likely to develop within cohorts of white American women with specific risk factors [23-25]. Therefore, in order to design meaningful prevention strategies, it is very important to identify these factors for each population and geographical location, and to understand the reasons of the observed differences. At present, there is no data available on the breast cancer risk factors for the Arab population. Therefore, in an attempt to identify and better define these risk factors for breast cancer among Arab women, we initiated the present case-control study.

\section{Methods}

\section{Study population}

The study cases were female patients with histologicalconfirmed primary breast cancer. We started interviewing patients, in the Oncology Department at King Faisal Specialist Hospital \& Research Center (KFSH\&RC) Riyadh. The controls were Saudi women aged 18 years or older, who visited the primary health care and were cancer free. Volunteers were enrolled in the study during the same calendar period as cases, from all Saudi provinces. Controls were randomly selected and approached while waiting for their doctor's appointment. Nearly $96 \%$ of women approached for the study chose to participate. KFSH\&RC is a tertiary care facility and serves as the main referring center for the whole Kingdom of Saudi Arabia (KSA). Therefore, it is conceivable that the cancer pattern seen at KFSH\&RC is a reflection to that seen in the whole country. This survey was carried out between June 2007 and August 2012. The study conformed to the principles outlined in the Declaration of Helsinki and was approved by the Research Ethics committee (Office of Research Affairs) at King Faisal Specialist Hospital \& Research Center, RAC-2031091.

\section{Data collection}

All study participants were interviewed by trained interviewers at hospital (cases) or at primary health care centers (controls). A structured questionnaire was used to elicit detailed information on demographic factors, menstrual and reproductive history, hormone use, dietary habits, prior disease history, physical activity, tobacco and alcohol use, and family history of cancer. Information on menstrual and reproductive history included age at menarche, menopausal status, age at menopause, pregnancy, and duration of breastfeeding for each live birth. Body height and weight were measured in light indoor clothing without shoes.

Obesity was assessed using BMI cutoffs standard criteria; BMI between 18.5 and 24.9 was considered normal, 25 to 29.9, overweight, and equal to or higher than 30, was considered obese. The education level was stratified into three categories: illiterate, primary or high school education and university studies.

\section{Data analysis}

Frequencies of categorical variables for cases and controls were computed. Tumor characteristics were cross-tabulated between pre-menopause and postmenopause and differences were assessed using $\chi^{2}$ test. Unconditional logistic regression analysis was performed to estimate odds ratios (ORs) and to examine the predictive effect of each factor on risk for breast cancer. Multiple logistic regressions were fitted to adjust for age ( $\leq 35$ years vs. $>35$ years), BMI (lean, overweight, obese), marital status (single, ever married), menopause status (pre-menopause, post-menopause), HRT use (yes/ no), age at menarche ( $<13$ years vs. $\geq 13$ years), breastfeeding (yes/no), and education levels (illiterate, primary/high school, higher education). Median age at menarche and median age at menopause were chosen as cutoffs values for categorical. For ordered categorical variables, P-value for linear trend was reported. All statistical assessments were two-sided and considered significant with p-value $<0.05$. Data analysis was carried out using $\mathrm{SAS}^{\odot}$ software (version 9.4; SAS Institute, Cary, NC).

\section{Results}

\section{Histological features of breast cancer cases in KSA}

In the present study we made use of 534 cases of histologically confirmed breast cancer and 638 controls. The age at diagnosis of the breast cancer cases ranged from 22 to 75 years with a mean of $43.6(\mathrm{SD}=8.3)$ years. While $49.7 \%$ of cases were premenopausal, $50.3 \%$ of cases were postmenopausal (Table 1). Tumors were of different stages and grades. Tumor stage I was $7.5 \%$; II, 50.7\%; II, 30.9\%; IV, $11.1 \%$. Figure 1 presents the distribution of age at diagnosis of breast cancer patients according to different classes of tumor stage left/right. The results show early mean age of diagnosis with advanced stage. Grade II and III tumors represented $56.7 \%$ and $38.4 \%$ of cases, respectively (Table 1). Furthermore, while Her-2 was negative in $54.6 \%$ of cases, ER-negative and PR-negative tumors represented $32.4 \%$ and $41.2 \%$ of cases respectively (Table 1 ). Interestingly, a significant association was observed between ER status and the menopausal status. Indeed, while $19.6 \%$ of premenopausal patients had ER-negative tumors, only 
Table 1 Tumor characteristics of the study cases

\begin{tabular}{|c|c|c|c|c|}
\hline Parameter & $\begin{array}{c}\text { Total (\%) } \\
\mathrm{N}=534\end{array}$ & $\begin{array}{c}\text { Pre-menopause } \\
n=266\end{array}$ & $\begin{array}{c}\text { Post-menopause } \\
n=267\end{array}$ & $p$-value \\
\hline \multicolumn{5}{|l|}{ Laterality } \\
\hline Left & $275(51.5)$ & $133(24.9)$ & $142(26.7)$ & \multirow{3}{*}{0.6945} \\
\hline Right & $250(46.8)$ & $129(24.1)$ & $120(22.6)$ & \\
\hline Bilateral & $9(1.7)$ & $4(0.75)$ & $5(0.94)$ & \\
\hline \multicolumn{5}{|l|}{ Stage Left } \\
\hline 1 & $14(5.0)$ & $7(2.5)$ & $7(2.5)$ & \multirow{4}{*}{0.9483} \\
\hline$\|$ & $147(52.5)$ & $73(26.1)$ & $74(26.5)$ & \\
\hline III & $90(32.1)$ & $42(15.0)$ & $48(17.2)$ & \\
\hline IV & $29(10.4)$ & $13(4.7)$ & $16(5.7)$ & \\
\hline \multicolumn{5}{|l|}{ Stage Right } \\
\hline I & $26(10.2)$ & $15(5.9)$ & $11(4.4)$ & \multirow[t]{4}{*}{0.0945} \\
\hline$\|$ & $123(48.2)$ & $67(26.4)$ & $56(22.1)$ & \\
\hline III & 76 (29.8) & 39 (15.4) & $36(14.2)$ & \\
\hline IV & $30(11.8)$ & 9 (3.6) & $21(8.3)$ & \\
\hline \multicolumn{5}{|l|}{ Grade } \\
\hline I & $25(4.9)$ & $15(3.0)$ & $10(2.0)$ & \multirow{3}{*}{0.5207} \\
\hline$\|$ & $285(56.7)$ & $141(28.2)$ & 143 (28.6) & \\
\hline III & $193(38.4)$ & 91 (18.2) & $100(20.0)$ & \\
\hline \multicolumn{5}{|l|}{ ER } \\
\hline Negative & $173(32.4)$ & 104 (19.6) & 69 (12.9) & \multirow{3}{*}{0.0037} \\
\hline Positive & $312(58.4)$ & $139(26.2)$ & $170(32.0)$ & \\
\hline Unknown & $49(9.2)$ & $21(3.9)$ & $28(5.3)$ & \\
\hline \multicolumn{5}{|l|}{ PR } \\
\hline Negative & $220(41.2)$ & $120(22.6)$ & 98 (18.5) & \multirow{3}{*}{0.1091} \\
\hline Positive & $265(49.6)$ & $123(23.2)$ & $141(26.6)$ & \\
\hline Unknown & $49(9.2)$ & $21(3.9)$ & $28(5.3)$ & \\
\hline \multicolumn{5}{|l|}{ Her_2 } \\
\hline Negative & $162(54.6)$ & 86 (29.3) & $74(25.2)$ & \multirow{3}{*}{0.5072} \\
\hline Positive & $132(44.4)$ & 77 (26.2) & $54(18.4)$ & \\
\hline Unknown & $3(1.0)$ & $1(0.34)$ & $2(0.68)$ & \\
\hline
\end{tabular}

Missing a pre-menopausal patient.

$12.9 \%$ of postmenopausal cases had ER-negative tumors $(p=0.0037)$ (Table 1).

\section{Breast cancer sociodemographic risk factors}

A total of 1172 women were eligible for this study, of which $281(24.0 \%)$ were aged $\leq 35$ years, $22.9 \%$ illiterate, $43.6 \%$ employed, $89.5 \%$ married, and $38.1 \%$ were obese. Family history of breast cancer, the marital status, education and occupation of breast cancer patients as well as healthy controls were investigated as sociodemographic risk factors of breast cancer among Arabs in KSA. Interestingly, higher proportion of cases (21.9\%) than controls (11.4\%) reported positive family history of breast cancer with high significance $(\mathrm{OR}=2.18,95 \%$ CI $1.58-2.99)$.
However, there was no significant difference between cases and controls regarding family history of other cancer $(p=0.9653)$ (Table 2).

Figure 2 shows significant associations between BMI and each of education, employment status and marital status. Illiterate, unemployed and married women had significantly higher mean BMI $(\mathrm{P}<0.0001)$. Education levels showed high association with marital status and employment in our population $(\mathrm{P}<0.0001)$. Among illiterate women, only $2.8 \%$ were working and $96.5 \%$ were married; whereas among highly educated women, $87.3 \%$ were employed and $80.4 \%$ were married (Figure 3 ).

Furthermore, Table 2 shows significant difference in education and occupation between cases and controls. Indeed, while higher proportion (50.9\%) of breast cancer females had received primary education as compared to controls (41.9\%), only $12.4 \%$ of cases had completed post-high school education as compared to controls $46.0 \%$. This indicates that lower level of education was associated with a significant increased risk of breast cancer in the Arab population $(p<0.0001)$. In line with this, $74.2 \%$ of the enrolled patients never worked as compared with control subjects $(57.8 \%)$, indicating that unemployment is significantly related to breast cancer development (OR $=3.94,95 \%$ CI $3.05-5.09$ ) (Table 2). Moreover, significant difference was found between cases and controls regarding marital status $(p<0.0001)$, with the marriage representing a risk factor in this population (Table 2).

\section{Breast cancer life style risk factors}

Alcohol is not available in KSA due to religion issues and therefore its consumption is not a risk factor for this population. Likewise, cigarette smoking was not a common practice among Arab females. Indeed, only $29.8 \%$ of cases and $28.8 \%$ of controls ever smoked. However, this difference was not statistically significant $(p=0.6995)$ (Table 2$)$, suggesting that cigarette smoking was not a risk factor for breast cancer in this population.

\section{Obesity is a significant breast cancer risk factor in the Arab population}

It became clear that obesity plays a major role in development and spread of breast cancer [26,27]. To elucidate the impact of this important risk factor on the Arab population, we investigated the link between breast cancer and obesity among cases and controls. Table 2 shows clear difference between patients and controls according to their BMI. The proportion of overweight/obese (BMI $\geq 25$ ) females was significantly higher among breast cancer patients $(75.8 \%)$ than among healthy controls (61.3\%) (OR $=1.74$ and $p<0.0001$ ). This clearly shows that obesity is a significant risk factor for breast cancer among Arab women. 

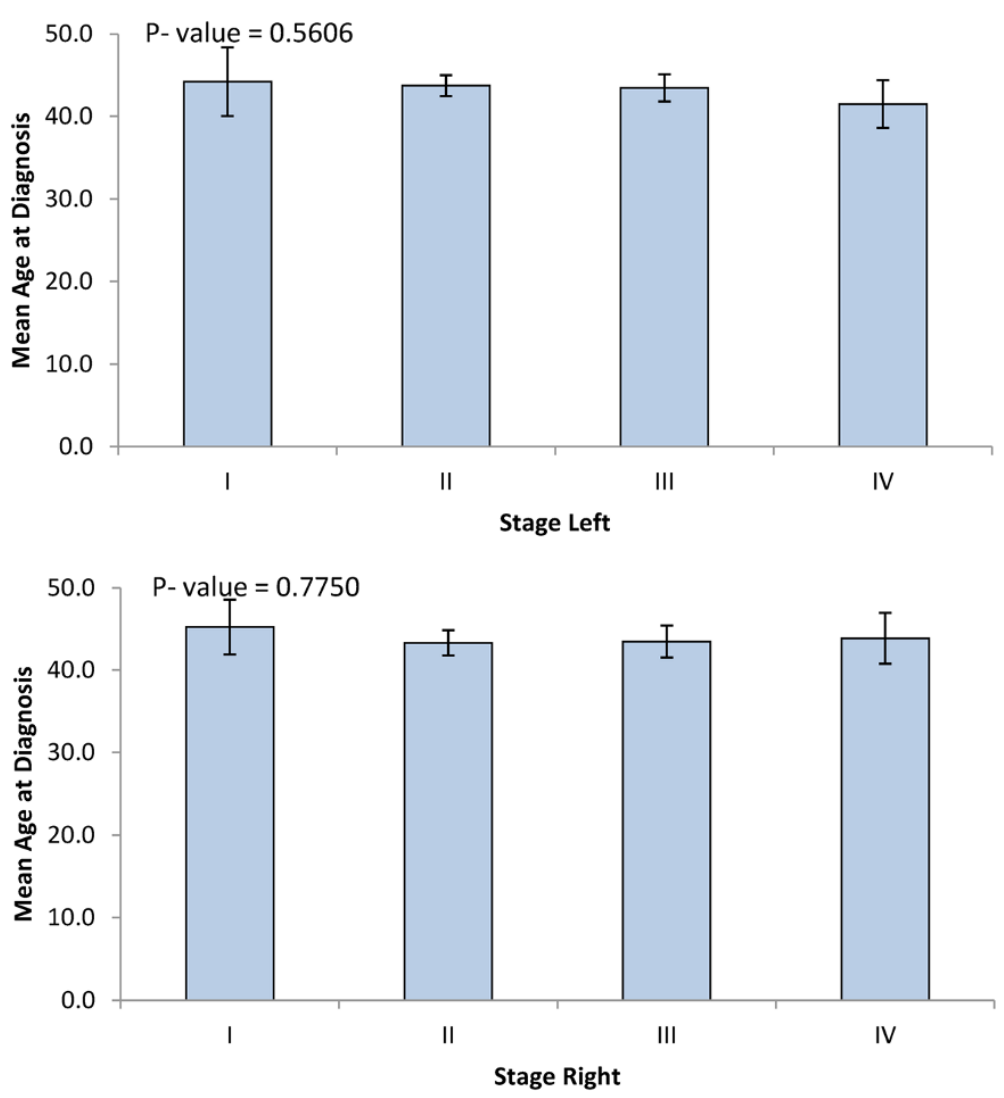

Figure 1 Least square means of age at diagnosis of breast cancer by stage.

When the menopausal status of cases was taken into consideration, we have found $74.7 \%$ of pre-menopausal patients were either overweight or obese, while only $58.5 \%$ of premenopausal controls exhibited BMI $\geq 30$ with ( $\mathrm{OR}=2.47, p<0.0001)$, indicating two-half fold increase in breast cancer risk among obese premenopausal patients (Table 2). In the post-menopausal females, obese women have $66 \%$ increase chance of breast cancer compared to lean post-menopause (Table 2).

\section{Breast cancer reproductive risk factors}

Table 3 shows that $49.7 \%$ of Arab breast cancer patients were pre-menopausal. However, more patients (50.3\%) were post-menopausal as compared to controls (23.5\%). This difference was highly significant $(p<0.0001)$, showing high breast cancer risk among post-menopausal females. Most of the Arab females (70.0\% cases and 92\% controls) reached menopause after 45 , and the age at menopause was observed to be associated with increased risk. Indeed, the odds of the risk are $80 \%$ lower in women who had menopause after 45 years of age $(\mathrm{OR}=0.20, \mathrm{P}=0.0001)$. Table 3 shows also that as many as $64.1 \%$ of Arab breast cancer patients have used hormonal replacement therapy (HRT) as compared to controls (47.7\%), indicating that the use of HRT doubled the chances of developing breast cancer ( $\mathrm{OR}=1.96, p<0.0001)$. On the other hand, no significant difference was found between cases and controls regarding breast feeding ( $p=0.8739)$ as well as age at menarche in univariate analysis $(p=0.0767)$ (Table 3 ).

\section{Independent breast cancer risk factors among Arabs}

Multivariate logistic regression analysis showed that factors that were independently associated with breast cancer are obesity (OR $=2.29,95 \%$ CI $1.68-3.13)$, positive family history of breast cancer (OR $=2.31,95 \%$ CI 1.60 3.32), HRT use (OR $=2.25,95 \%$ CI $1.65-3.08)$, postmenopause ( $\mathrm{OR}=1.72,95 \%$ CI $1.25-2.38)$, late age of menarche (OR $=1.30,95 \%$ CI $0.99-1.72)$, never breastfeed $(\mathrm{OR}=1.89,95 \%$ CI $1.19-2.94)$, and lack of education $(\mathrm{OR}=9.09,95 \%$ CI $5.88-14.29)$ (Table 4).

\section{Discussion}

Identification of risk factors and women at high risk for developing breast cancer is highly important for preventing the development of the disease. Owing to the paucity of such data among Arab females, we decided to assess here the strength of association between recognized sociodemographic, reproductive and anthropometric risk factors for breast cancer among Arabs in KSA. This is the first case-control epidemiological investigation on breast 
Table 2 Socio-demographical characteristics of the Saudi breast cancer cases and controls

\begin{tabular}{|c|c|c|c|c|}
\hline Socio-demographic characteristics & Cases number (\%) & Control number (\%) & OR $95 \%$ confidence intervals & $P$-value \\
\hline Age, years & & & & $<0.0001$ \\
\hline$\leq 35$ & $80(15.0)$ & $201(31.5)$ & 1 & \\
\hline$>35$ & $454(85.0)$ & $437(68.5)$ & $2.61(1.95-3.49)$ & \\
\hline Family History of Breast Cancer & $117(21.9)$ & $72(11.4)$ & $2.18(1.58-2.99)$ & $<0.0001$ \\
\hline Family History of Cancer & $221(41.4)$ & $262(41.3)$ & $1.01(0.80-1.27)$ & 0.9653 \\
\hline Education Level & & & & $<0.0001$ \\
\hline Illiterate-no schooling & $183(36.7)$ & $76(12.1)$ & 1 & \\
\hline $1-12$ years & $254(50.9)$ & $264(41.9)$ & $0.40(0.29-0.55)$ & \\
\hline$>12$ years & $62(12.4)$ & $290(46.0)$ & $0.09(0.06-0.13)$ & \\
\hline Ever Married (no) & $23(4.3)$ & $100(15.7)$ & $0.24(0.15-0.39)$ & $<0.0001$ \\
\hline Never Worked & $368(74.2)$ & $263(42.2)$ & $3.94(3.05-5.09)$ & $<0.0001$ \\
\hline Ever Smoke (yes) & $158(29.8)$ & $181(28.8)$ & $1.05(0.82-1.36)$ & 0.6995 \\
\hline \multicolumn{5}{|c|}{$\mathrm{BMI}, \mathrm{kg} / \mathrm{m}^{2}$} \\
\hline \multicolumn{5}{|l|}{ All } \\
\hline Lean & $129(24.2)$ & $247(38.7)$ & 1 & \multirow{3}{*}{$<0.0001$} \\
\hline Overweight & $157(29.4)$ & $193(30.3)$ & $1.56(1.15-2.10)$ & \\
\hline Obese & $248(46.4)$ & 198 (31.0) & $2.40(1.81-3.18)$ & \\
\hline \multicolumn{5}{|l|}{ Pre-Menopause } \\
\hline Lean & $67(25.4)$ & $201(41.5)$ & 1 & \multirow{3}{*}{$<0.0001$} \\
\hline Overweight & 86 (32.6) & 148 (30.6) & $1.74(1.19-2.56)$ & \\
\hline Obese & $111(42.1)$ & $135(27.9)$ & $2.47(1.70-3.58)$ & \\
\hline \multicolumn{5}{|l|}{ Post-Menopause } \\
\hline Lean & $60(22.5)$ & $45(30.2)$ & 1 & \multirow{3}{*}{0.1191} \\
\hline Overweight & $70(26.2)$ & $42(28.2)$ & $1.25(0.73-2.15)$ & \\
\hline Obese & $137(51.3)$ & $62(41.6)$ & $1.66(1.02-2.70)$ & \\
\hline
\end{tabular}

Abbreviations: $O R$ odds ratio, $B M I$ body mass index.

Lean: BMI (18.5 - 24.9); Overweight: BMI (25 - 29.9); Obese: BMI $(\geq 30)$.

cancer risk factors in KSA. We have found that many established risk factors are also associated with breast cancer among Arab females, and therefore coincide with results of Western populations in this regard. Among the well-established risk factors of breast cancer, only obesity, positive family history of breast cancer, use of hormonal replacement therapy, education and employment status were significantly associated with higher risks of breast cancer in this population.

In the present study, we have shown that family history of breast cancer is an independent predictor of breast cancer. Women with a positive family history of breast cancer showed about threefold increased risk of breast cancer (OR $=2.31, p<0.0001)$. This parallels what has been previously reported in various populations in different geographical regions $[28,29]$. This also reflects the role of genetic and epigenetic modifications at important genes such as $B R C A 1$ and $B R C A 2$ in the predisposition to the disease [30]. However, no association was observed between the development of the disease and the presence of other types of cancer in the family.

Using BMI as reference, we found $75.8 \%$ of the cases had abnormal weight. Obesity was found to be associated with breast cancer. Overweight/Obese women exhibit more than 2-fold increased risk of breast cancer $(\mathrm{OR}=2.29)$ compared to women with normal BMI. Our data support the concept that obesity is a strong risk factor for the disease, which is consistent with previous reports on different populations in various regions [26,31]. In the Arab population, breast cancer risk was significantly higher among females who were overweight or obese both pre- and post-menopausal ( $\mathrm{OR}=2.73$ and $\mathrm{OR}=2.22$ respectively; $p<0.0001)$. On the other hand, obesity was shown to play a protective effect against developing breast cancer in premenopausal Caucasian females [26], while other studies have shown no association between obesity and breast cancer risk [29]. This discrepancy may have several explanations, including the implication of genetic and/or 

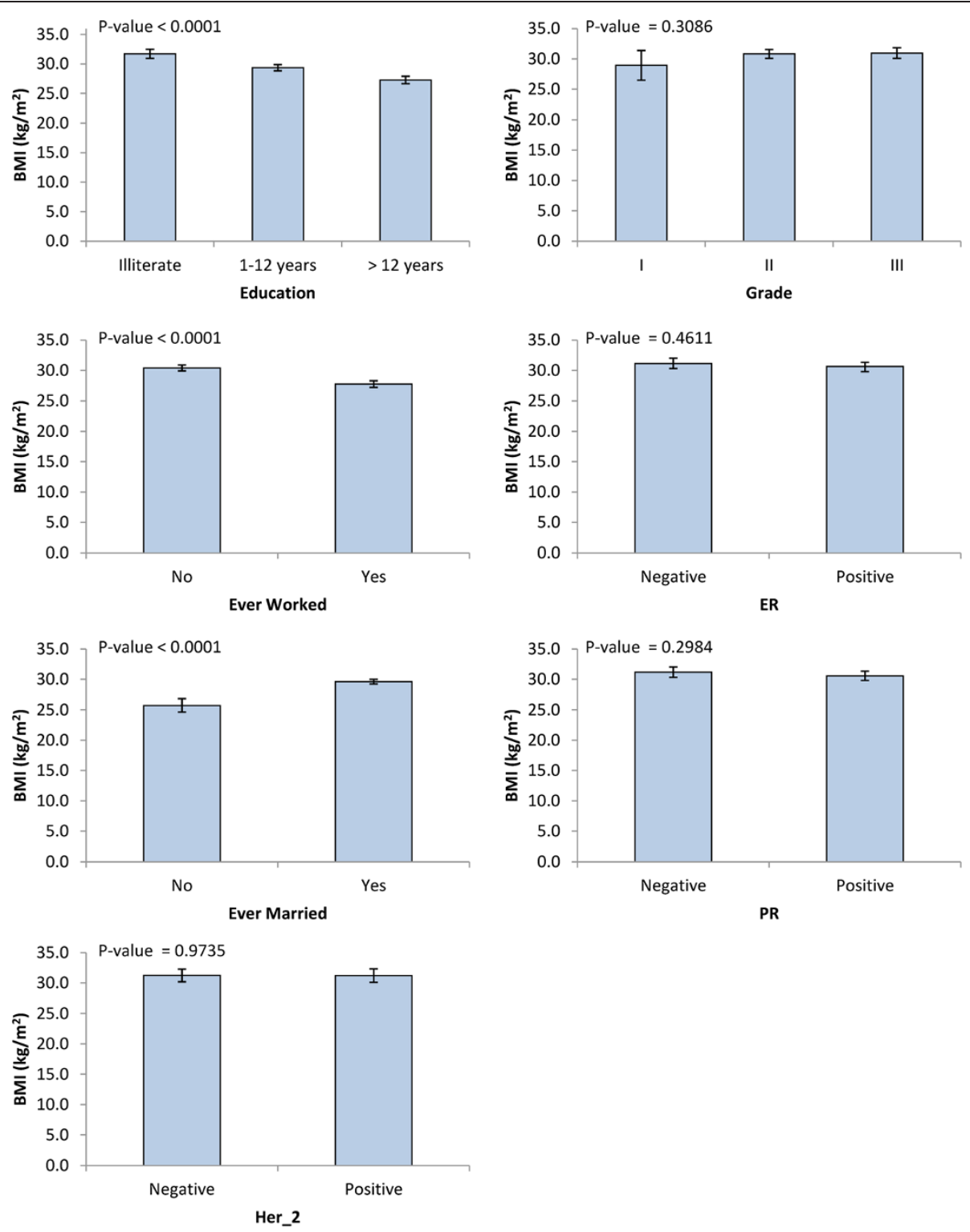

Figure 2 Least square means of BMI according to various breast cancer risk factors.

environmental factors in the obesity-related development of the disease or physical inactivity. Generally, people in the Gulf countries are physically inactive and spend their leisure time in sedentary activities [32]. Therefore, appropriate measures need to be taken by the healthcare planners to prevent weight gain and obesity that will probably be more cost effective than the treatment of breast cancer and related complications. Furthermore, preventive lifestyle interventions should be targeted at lowering overweight in Arab women.

We have also observed positive association between HRT and breast cancer; confirming the fact that use of HRT increases breast cancer risk. Previous studies have concluded that combinations of estrogen-progesterone increase the risk of breast cancer for women who were treated for at least 5-years [33,34]. Our data show that using HRT doubles the chance of developing the disease among Arab females.

Breast cancer among Arab females is significantly related with the level of education. Indeed, lack of education was an independent risk factor for breast cancer and was 6 times more common among illiterate females as compared to the highly educated ones, and the risk decreases as the level of education increases. Women with higher education might have healthier lifestyle, which could play a key role in preventing the disease.

Our results showed that breastfeeding has a protective effect against breast cancer development. Cases were less 

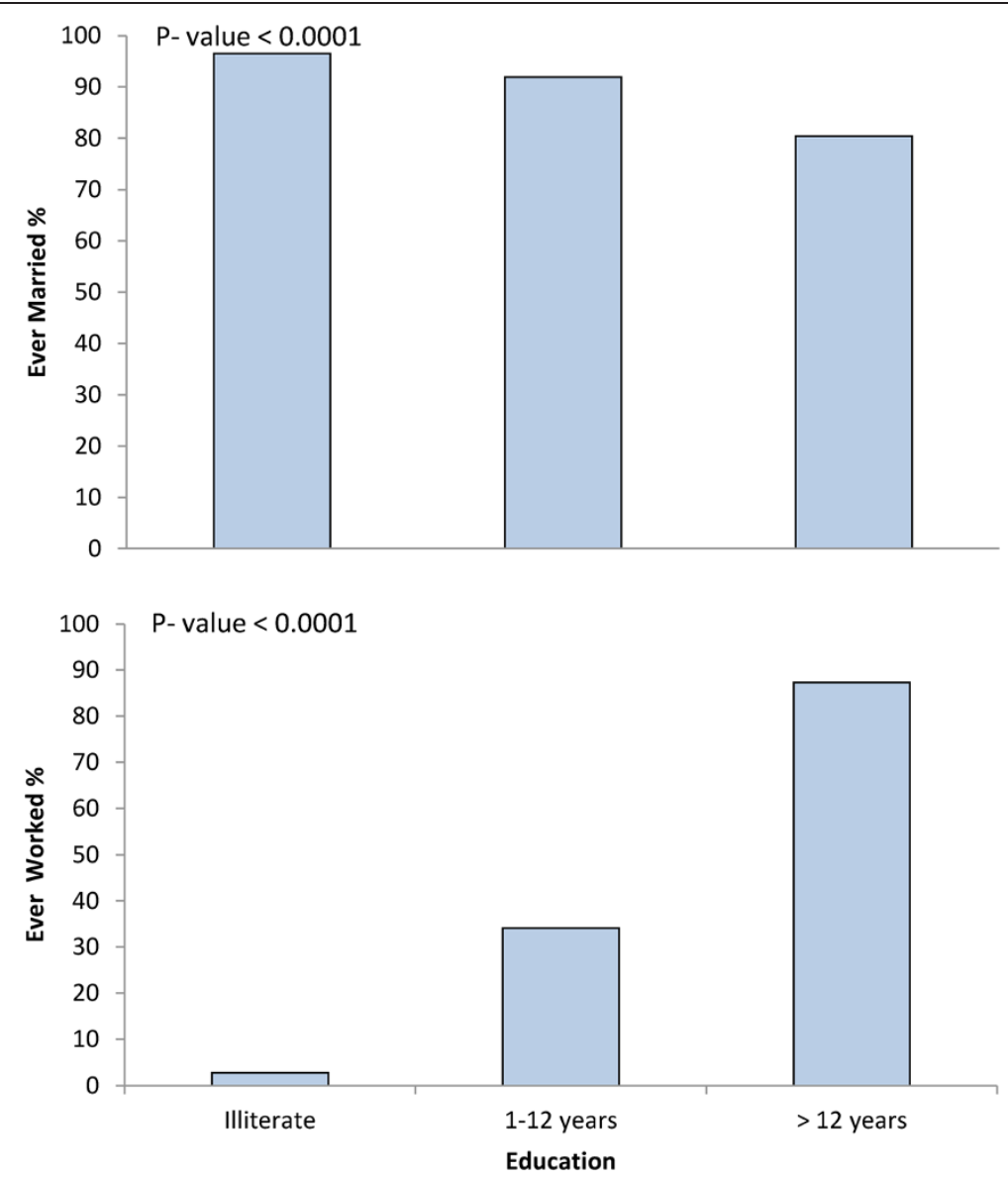

Figure 3 The proportion of married and employed women by education levels.

Table 3 Reproductive characteristics of Saudi breast cancer cases and controls

\begin{tabular}{|c|c|c|c|c|}
\hline Parameter & Cases number (\%) & Controls number (\%) & OR $95 \%$ confidence intervals & P-values \\
\hline \multicolumn{5}{|l|}{ Menopausal Status } \\
\hline Pre-menopause & $264(49.7)$ & $484(76.5)$ & 1 & \multirow[t]{2}{*}{$<0.0001$} \\
\hline Postmenopausal & $267(50.3)$ & $149(23.5)$ & $3.29(2.56-4.22)$ & \\
\hline \multicolumn{5}{|c|}{ Age at menarche (years) } \\
\hline$<13$ & $379(70.9)$ & $422(66.1)$ & 1 & \multirow[t]{2}{*}{0.0767} \\
\hline$\geq 13$ & $155(29.1)$ & $216(33.9)$ & $0.80(0.62-1.03)$ & \\
\hline \multicolumn{5}{|l|}{ Breastfeeding } \\
\hline No & $38(8.0)$ & $38(8.0)$ & 1 & \multirow[t]{2}{*}{0.8739} \\
\hline Yes & $440(92.1)$ & $457(92.0)$ & $0.96(0.60-1.54)$ & \\
\hline \multicolumn{5}{|c|}{ Use of hormonal replacement therapy } \\
\hline No & $191(35.9)$ & $329(52.3)$ & 1 & \multirow[t]{2}{*}{$<0.0001$} \\
\hline Yes & $341(64.1)$ & $300(47.7)$ & $1.96(1.55-2.48)$ & \\
\hline \multicolumn{5}{|c|}{ Age at menopause (years) } \\
\hline$<45$ & $67(30.0)$ & $7(8.0)$ & 1 & \multirow[t]{2}{*}{0.0001} \\
\hline$\geq 45$ & $156(70.0)$ & $81(92)$ & $0.20(0.09-0.46)$ & \\
\hline
\end{tabular}

Median values were used as cutoff point for age at menopause and age at menarche. Abbreviation: $O R$ odds ratio. 
Table 4 Factors independently associated with Saudi breast cancer women - multiple logistic regression

\begin{tabular}{|c|c|c|c|}
\hline \multirow[t]{2}{*}{ Parameters } & All & Pre-menopausal & Post-menopause \\
\hline & \multicolumn{2}{|l|}{ OR (95\% Cl) } & \\
\hline \multicolumn{4}{|l|}{$\mathrm{BMI}, \mathrm{kg} / \mathrm{m}^{2}$} \\
\hline Lean, (18.5 - 24.9) & 1 & 1 & 1 \\
\hline Overweight/Obese ( $\geq 25$ ) & $2.29(1.68-3.13)$ & $2.73(1.79-4.18)$ & $2.22(1.32-3.72)$ \\
\hline Family history of breast cancer & & & - \\
\hline No & 1 & 1 & \\
\hline Yes & $2.31(1.60-3.32)$ & $5.04(3.09-8.21)$ & \\
\hline Age at menarche (years) & & - & - \\
\hline$<13$ & 1 & & \\
\hline$\geq 13$ & $1.30(0.99-1.72)$ & & \\
\hline \multicolumn{4}{|l|}{ Use of HRT } \\
\hline No & 1 & 1 & 1 \\
\hline Yes & $2.25(1.65-3.08)$ & $1.73(1.13-2.67)$ & $2.45(1.53-3.92)$ \\
\hline Menopausal Status & & - & - \\
\hline Pre-menopause & 1 & & \\
\hline Post-menopause & $1.72(1.25-2.38)$ & & \\
\hline \multicolumn{4}{|l|}{ Breastfeeding } \\
\hline No & 1 & & 1 \\
\hline Yes & $0.53(0.34-0.84)$ & & $0.20(0.08-0.50)$ \\
\hline \multicolumn{4}{|l|}{ Education Level } \\
\hline Illiterate & 1 & 1 & 1 \\
\hline Primary/High School & $0.40(0.28-0.58)$ & $0.11(0.06-0.27)$ & $0.73(0.44-1.20)$ \\
\hline Higher education & $0.11(0.07-0.17)$ & $0.03(0.01-0.07)$ & $0.21(0.10-0.45)$ \\
\hline
\end{tabular}

Model adjusted for age ( $\leq 35$ years vs. $>35$ years), BMI (lean, overweight/obese), marital status (single, ever-married), menopause status (pre-menopause, post-menopause), HRT use (yes/no), age at menarche ( $<13$ years vs. $\geq 13$ years), breastfeeding (yes/no), and education levels (illiterate, primary/high school, higher education). All variables in the model are categorical.

Abbreviations: $O R$ odds ratio, $C l$ confidence interval, $B M I$ body mass index.

likely than controls to have breastfeed $(\mathrm{OR}=0.51)$. This finding is consistent with the results of many other studies [29,35-37]. Further investigations are recommended to understand the underlying mechanisms of the influence of breastfeeding on breast cancer.

It is well established that breast cancer risk increases with early age at menarche [16]. Surprisingly, we observed an inverse association between early age at menarche and breast cancer risk. Similar result has been recently reported in the Chinese population [38]. This suggests that early age at menarche represents a protective factor in these populations. This may be due to genetic and/or environmental factors.

Finally, this study showed for the first time a number of risk factors associated with incidence of breast cancer among Arab women. The strongest associations were family history of breast cancer, obesity, use of HRT, being post-menopause, illiterate, and having never breastfeed.

Our study had limitations commonly seen in this type of studies. While cases were only from one hospital, which is a tertiary care facility that serves as the main referring center for the whole Kingdom of Saudi Arabia, cases were collected from different regions of the country. This may constitute a bias as to the origin of the patients/controls. Furthermore, controls were all recruited from hospitals. Our sample size of 534 cases and 638 controls may seem rather small for such studies. Another limitation is that BMI, which may change with time, was measured only once for both patients and controls.

\section{Conclusions}

In conclusion, among other risk factors, obesity increases the breast cancer risk in pre- and post-menopause Arab women. Given the fact that obesity is common among this population, there is a need for education campaigns publicizing obesity as an important risk factor for breast cancer and encouraging Arab females to exercise and pursue healthy lifestyle. 


\section{Consent}

Written informed consent was obtained from the patient for the publication of this report and any accompanying images.

\section{Competing interests}

The authors declare they have no competing interests.

\section{Authors' contributions}

NE participated in the conception and overall supervision of the study, handled data management, data analysis, and wrote the manuscript. $T$ and DA selected cases, reviewed medical records, and editing of the manuscript; AAZ and SM conceived of the study and participated in its coordination; AA participated in the study conception, data interpretation and developing and writing of the manuscript. All authors have read and approved the final version of the manuscript.

\section{Acknowledgements}

We are very grateful to the administration of the Research Centre and the Research Advisory Council (RAC) for their continuous support. We would also thank Ingrid Osmond for her proofreading of the manuscript and helpful comments. This work was performed under the RAC proposal \# 2031091. Grant sponsor: King Abdulaziz City for Science and Technology (KACST \# APR-24-32).

\section{Author details}

'Division of Clinical Epidemiology, Sidra Medical and Research Centre, Doha, Qatar. ${ }^{2}$ Department of Medical Oncology, KFSH\&RC, Oncology Centre, MBC\#64, KSA, Riyadh, Saudi Arabia. ${ }^{3}$ Department of Molecular Oncology, KFSH\&RC, MBC \# 03, KSA, Riyadh, Saudi Arabia. ${ }^{4}$ Department of Biostatistics, Epidemiology, and Scientific Computing, KFSH\&RC, MBC\#03, KSA, Riyadh, Saudi Arabia.

Received: 24 February 2014 Accepted: 17 October 2014

Published: 29 October 2014

\section{References}

1. Jemal A, Bray F, Center MM, Ferlay J, Ward E, Forman D: Global cancer statistics. CA Cancer J Clin 2011, 61(2):69-90.

2. Youlden DR, Cramb SM, Dunn NA, Muller JM, Pyke CM, Baade PD: The descriptive epidemiology of female breast cancer: an international comparison of screening, incidence, survival and mortality. Cancer Epidemiol 2012, 36(3):237-248.

3. El Saghir NS, Khalil MK, Eid T, El Kinge AR, Charafeddine M, Geara F, Seoud M, Shamseddine Al: Trends in epidemiology and management of breast cancer in developing Arab countries: a literature and registry analysis. Int I Surg 2007, 5(4):225-233.

4. Ravichandran K, Al-Zahrani AS: Association of reproductive factors with the incidence of breast cancer in Gulf Cooperation Council countries. East Mediterr Health J 2009, 15(3):612-621.

5. Al-Hamdan N, Ravichandran K, Al-Sayyad J, Al-Lawati J, Khazal Z, Al-Khateeb F, Abdulwahab A, Al-Asfour A: Incidence of cancer in Gulf Cooperation Council countries, 1998-2001. East Mediterr Health J 2009, 15(3):600-611.

6. Al-Madouj A, Eldali A, Al-Zahrani A: Ten-Year Cancer Incidence Among Nationals of the GCC States 1998-2007. Riyadh: Corperation Council States; 2011.

7. Ezzat AA, Ibrahim EM, Raja MA, Al-Sobhi S, Rostom A, Stuart RK: Locally advanced breast cancer in Saudi Arabia: high frequency of stage III in a young population. Med Oncol 1999, 16(2):95-103.

8. Ibrahim EM, Ezzat AA, Rahal MM, Raja MM, Ajarim DS: Adjuvant chemotherapy in 780 patients with early breast cancer: 10-year data from Saudi Arabia. Med Oncol 2005, 22(4):343-352.

9. Elkum N, Dermime S, Ajarim D, Al-Zahrani A, Alsayed A, Tulbah A, Al Malik $\mathrm{O}$, Alshabanah M, Ezzat A, Al-Tweigeri T: Being 40 or younger is an independent risk factor for relapse in operable breast cancer patients: the Saudi Arabia experience. BMC Cancer 2007, 7:222.

10. Najjar $\mathrm{H}$, Easson $\mathrm{A}$ : Age at diagnosis of breast cancer in Arab nations. Int $\mathrm{J}$ Surg 2010, 8(6):448-452.

11. Dubsky PC, Gnant MF, Taucher S, Roka S, Kandioler D, Pichler-Gebhard B, Agstner I, Seifert M, Sevelda P, Jakesz R: Young age as an independent adverse prognostic factor in premenopausal patients with breast cancer. Clin Breast Cancer 2002, 3(1):65-72.

12. Rosner B, Colditz GA, Willett WC: Reproductive risk factors in a prospective study of breast cancer: the Nurses' Health Study. Am J Epidemiol 1994, 139(8):819-835.

13. Kelsey JL, Gammon MD, John EM: Reproductive factors and breast cancer. Epidemiol Rev 1993, 15(1):36-47.

14. Kelsey JL, Horn-Ross PL: Breast cancer: magnitude of the problem and descriptive epidemiology. Epidemiol Rev 1993, 15(1):7-16.

15. Lipworth L: Epidemiology of breast cancer. Eur J Cancer Prev 1995, 4(1):7-30

16. Dumitrescu RG, Cotarla I: Understanding breast cancer risk - where do we stand in 2005? J Cell Mol Med 2005, 9(1):208-221

17. Thompson D, Easton D: The genetic epidemiology of breast cancer genes. J Mammary Gland Biol Neoplasia 2004, 9(3):221-236.

18. Bray F, McCarron P, Parkin DM: The changing global patterns of female breast cancer incidence and mortality. Breast Cancer Res 2004, 6(6):229-239.

19. Parkin DM, Bray F, Ferlay J, Pisani P: Global cancer statistics, 2002. CA Cancer J Clin 2005, 55(2):74-108.

20. McPherson K, Steel CM, Dixon KM: ABC of breast diseases. Breast cancerepidemiology, risk factors, and genetics. BMJ 2000, 321(7261):624-628.

21. Perera NM, Gui GP: Multi-ethnic differences in breast cancer: current concepts and future directions. Int J Cancer 2003, 106(4):463-467.

22. Sprague BL, Trentham-Dietz A, Egan KM, Titus-Ernstoff L, Hampton JM, Newcomb PA: Proportion of invasive breast cancer attributable to risk factors modifiable after menopause. Am J Epidemio/ 2008, 168(4):404-411.

23. Euhus DM: Understanding mathematical models for breast cancer risk assessment and counseling. Breast J 2001, 7(4):224-232.

24. van Asperen CJ, Jonker MA, Jacobi CE, van Diemen-Homan JE, Bakker E, Breuning $\mathrm{MH}$, van Houwelingen JC, de Bock GH: Risk estimation for healthy women from breast cancer families: new insights and new strategies. Cancer Epidemiol Biomarkers Prev 2004, 13(1):87-93.

25. Jacobi $C E$, de Bock GH, Siegerink B, van Asperen CJ: Differences and similarities in breast cancer risk assessment models in clinical practice: which model to choose? Breast Cancer Res Treat 2009, 115(2):381-390

26. Majed B, Moreau T, Senouci K, Salmon RJ, Fourquet A, Asselain B: Is obesity an independent prognosis factor in woman breast cancer? Breast Cancer Res Treat 2008, 111(2):329-342.

27. Amadou A, Hainaut $P$, Romieu I: Role of obesity in the risk of breast cancer: lessons from anthropometry. J Oncol 2013, 2013:906495.

28. Collaborative Group on Hormonal Factors in Breast Cancer: Familial breast cancer: collaborative reanalysis of individual data from 52 epidemiological studies including 58,209 women with breast cancer and 101,986 women without the disease. Lancet 2001, 358(9291):1389-1399.

29. Hadjisavvas A, Loizidou MA, Middleton N, Michael T, Papachristoforou R, Kakouri E, Daniel M, Papadopoulos P, Malas S, Marcou Y, Kyriacou K: An investigation of breast cancer risk factors in Cyprus: a case control study. BMC Cancer 2010, 10:447.

30. el El-Harith HA, Abdel-Hadi MS, Steinmann D, Dork T: BRCA1 and BRCA2 mutations in breast cancer patients from Saudi Arabia. Saudi Med J 2002, 23(6):700-704.

31. Deglise C, Bouchardy C, Burri M, Usel M, Neyroud-Caspar I, Vlastos G, Chappuis PO, Ceschi M, Ess S, Castiglione M, Rapiti E, Verkooijen HM: Impact of obesity on diagnosis and treatment of breast cancer. Breast Cancer Res Treat 2010, 120(1):185-193.

32. Mabry RM, Reeves MM, Eakin EG, Owen N: Evidence of physical activity participation among men and women in the countries of the Gulf cooperation council: a review. Obes Rev 2010, 11(6):457-464.

33. Beral V: Breast cancer and hormone-replacement therapy in the Million Women Study. Lancet 2003, 362(9382):419-427.

34. Collaborative-Group-on-Hormonal-Factors-in-Breast-Cancer: Breast cancer and hormone replacement therapy: collaborative reanalysis of data from 51 epidemiological studies of 52,705 women with breast cancer and 108,411 women without breast cancer. Lancet 1997, 350(9084):1047-1059.

35. Kumar, Babita N, Singh M, Malik JS, Kalhan M: Breastfeeding reduces breast cancer risk: a case-control study in north India. Int J Prevent MEd 2014, 5(6):791-795.

36. Newcomb PA, Storer BE, Longnecker MP, Mittendorf R, Greenberg ER, Clapp RW, Burke KP, Willett WC, MacMahon B: Lactation and a reduced risk of premenopausal breast cancer. N Engl J Med 1994, 330(2):81-87.

37. Kotsopoulos J, Lubinski J, Salmena L, Lynch HT, Kim-Sing C, Foulkes WD, Ghadirian P, Neuhausen SL, Demsky R, Tung N, Ainsworth P, Senter L, Eisen 
A, Eng C, Singer C, Ginsburg O, Blum J, Huzarski T, Poll A, Sun P, Narod SA: Breastfeeding and the risk of breast cancer in BRCA1 and BRCA2 mutation carriers. Breast Cancer Res 2012, 14(2):R42.

38. Xu YL, Sun Q, Shan GL, Zhang J, Liao HB, Li SY, Jiang J, Shao ZM, Jiang HC, Shen NC, Shi Y, Yu CZ, Zhang BN, Chen YH, Duan XN, Li B: A case-control study on risk factors of breast cancer in China. Arch Med Sci 2012 8(2):303-309.

doi:10.1186/1471-2407-14-788

Cite this article as: Elkum et al:: Obesity is a significant risk factor for breast cancer in Arab women. BMC Cancer 2014 14:788.

\section{Submit your next manuscript to BioMed Central and take full advantage of:}

- Convenient online submission

- Thorough peer review

- No space constraints or color figure charges

- Immediate publication on acceptance

- Inclusion in PubMed, CAS, Scopus and Google Scholar

- Research which is freely available for redistribution 